\title{
Relationship Among Emotional Intelligence and/or Extrovert Bias on Perceived Stress Levels in DPT Students
}

\author{
Scott Richardson \\ Franklin Pierce University, richardsons@franklinpierce.edu \\ Jordan Auvinen \\ Franklin Pierce University, Auvinenj17@live.franklinpierce.edu \\ Brennan Bonnett \\ Franklin Pierce University, Bonnettb17@live.franklinpierce.edu \\ Lucas Takeuchi \\ Franklin Pierce University, Takeuchil17@live.franklinpierce.edu \\ Erin Thompson \\ Franklin Pierce University, Thompsone17@live.franklinpierce.edu
}

Follow this and additional works at: https://nsuworks.nova.edu/ijahsp

Part of the Physical Therapy Commons

\section{Recommended Citation}

Richardson S, Auvinen J, Bonnett B, Takeuchi L, Thompson E. Relationship Among Emotional Intelligence and/or Extrovert Bias on Perceived Stress Levels in DPT Students. The Internet Journal of Allied Health Sciences and Practice. 2021 Jan 01;19(2), Article 8.

This Manuscript is brought to you for free and open access by the College of Health Care Sciences at NSUWorks. It has been accepted for inclusion in Internet Journal of Allied Health Sciences and Practice by an authorized editor of NSUWorks. For more information, please contact nsuworks@nova.edu. 


\title{
Relationship Among Emotional Intelligence and/or Extrovert Bias on Perceived Stress Levels in DPT Students
}

\begin{abstract}
Purpose/Hypothesis: Students in graduate level DPT programs function at varying levels. Some students thrive and others struggle to maintain required minimum levels of academic performance. When considering admission of applicants, and when assisting enrolled students, consideration of factors contributing to academic success is of interest. Stress has been shown to be prevalent in a wide range of students and has many negative effects including poor life satisfaction, increased clinical burnout, and reduced academic performance. Research has shown a correlation between higher emotional intelligence (EI) and decreased stress levels in medical, nursing, and undergraduate students. The purpose of this study was to examine if emotional intelligence (EI) and/or extrovert bias correlates with perceived stress levels in Doctor of Physical Therapy (DPT) students. It was hypothesized that students with higher emotional intelligence and more extroverted personalities would experience lower levels of perceived stress.
\end{abstract}

Participants: After providing consent, a convenience sample of 60 first and second year DPT students (33 female) with age range 23 to 38 participated in the current study. Participation was voluntary and 60 of a possible 72 students chose to participate.

Materials/Methods: After obtaining informed consent, participants completed Goldberg's IPIP-Neo questionnaire (extraversion), Perceived Stress Scale (PSS) and Assessing Emotions Scale (emotional intelligence). Each of these tools have demonstrated validity and reliability for the respective areas measured. Surveys were administered to students and results were analyzed for possible relationships between extraversion and stress levels as well as El and stress levels using a Spearman Correlation test.

Results: Spearman Correlation analyses were conducted with a significant negative correlation between El and perceived stress $r_{s}=-0.291, p=0.026$ and a non-significant negative correlation between extraversion and perceived stress $r_{s}=-1.36, p=0.305$.

Discussion: In the current sample, El had a significant negative relationship with perceived stress levels, with higher El scores correlating to lower levels of stress. The relationship between extraversion and perceived stress was non-significant.

Clinical Relevance: Doctorate level graduate programs can be considered intense and very stressful. Admission of qualified students equipped to meet the demands of a DPT program has great importance. Establishing a correlation between El, introversion/extraversion bias, and stress may help DPT programs further assess prospective students. Consideration of factors correlated with higher perceived stress may be useful when providing resources to admitted students to facilitate academic success.

\section{Author Bio(s)}

Scott Richardson, PT, PhD, is an Assistant Professor in the College of Health and Natural Sciences at Franklin Pierce University. He has also earned the Advanced Competency in Home Health from the American Physical Therapy Association. 


\title{
1IJAHSP \\ The Internet Journal of Allied Health Sciences and Practice \\ Dedicated to allied health professional practice and education
}

Vol. 19 No. 1 ISSN 1540-580X

\section{Relationship Among Emotional Intelligence and/or Extrovert Bias on Perceived Stress Levels in DPT Students}

\author{
Scott Richardson \\ Jordan Auvinen \\ Brennan Bonnett \\ Lucas Takeuchi \\ Erin Thompson
}

Franklin Pierce University

United States

\begin{abstract}
Purpose: Students in graduate level DPT programs function at varying levels. Some students thrive and others struggle to maintain required minimum levels of academic performance. When considering admission of applicants, and when assisting enrolled students, consideration of factors contributing to academic success is of interest. Stress has been shown to be prevalent in a wide range of students and has many negative effects including poor life satisfaction, increased clinical burnout, and reduced academic performance. Research has shown a correlation between higher emotional intelligence (EI) and decreased stress levels in medical, nursing, and undergraduate students. The purpose of this study was to examine if emotional intelligence (EI) and/or extrovert bias correlates with perceived stress levels in Doctor of Physical Therapy (DPT) students. It was hypothesized that students with higher emotional intelligence and more extroverted personalities would experience lower levels of perceived stress. Participants: After providing consent, a convenience sample of 60 first and second year DPT students ( 33 female) with age range 23 to 38 participated in the current study. Participation was voluntary, and 60 of a possible 72 students chose to participate. Methods: After obtaining informed consent, participants completed Goldberg's IPIP-Neo questionnaire (extraversion), Perceived Stress Scale (PSS) and Assessing Emotions Scale (emotional intelligence). Each of these tools have demonstrated validity and reliability for the respective areas measured. Surveys were administered to students, and results were analyzed for possible relationships between extraversion and stress levels as well as El and stress levels using a Spearman Correlation test. Results: Spearman Correlation analyses were conducted with a significant negative correlation between El and perceived stress $r_{s}=-0.291, p=0.026$ and a nonsignificant negative correlation between extraversion and perceived stress $r_{s}=-1.36, p=0.305$. Discussion: In the current sample, El had a significant negative relationship with perceived stress levels, with higher El scores correlating to lower levels of stress. The relationship between extraversion and perceived stress was non-significant. Clinical Relevance: Doctorate level graduate programs can be considered intense and very stressful. Admission of qualified students equipped to meet the demands of a DPT program has great importance. Establishing a correlation between El, introversion/extraversion bias, and stress may help DPT programs further assess prospective students. Consideration of factors correlated with higher perceived stress may be useful when providing resources to admitted students to facilitate academic success.
\end{abstract}

Keywords: emotional intelligence, perceived stress, introvert, extrovert, physical therapy 


\section{INTRODUCTION}

It is well documented that high levels of perceived stress are prevalent among students receiving medical, dental, nursing, physical therapy and undergraduate training. ${ }^{1,4-16}$ Stress has been widely studied with many detrimental health effects identified including gastrointestinal and cardiac problems and psychological issues such as poor mood control and inability to experience pleasure. ${ }^{17,18}$ Stress also results in poor student life satisfaction as well as student failure or burnout.2,13,19-21 Stress has also been shown to correlate with decreased academic performance in undergraduate and medical students. ${ }^{22-26}$

Non-cognitive traits, such as emotional intelligence (EI), enable students to effectively manage stress and perform at higher levels in rigorous educational programs. ${ }^{27-29}$ Emotional intelligence is defined as "the ability to perceive emotions, to access and generate emotions so as to assist thought, to understand emotions and emotional knowledge, and to reflectively regulate emotions so as to promote emotional and intellectual growth."30 Several studies have demonstrated that higher levels of El relate to lower perceived stress in undergraduate students, dental, medical, nursing ${ }^{6}$ students, and also in a multi-institutional study studying students from various healthcare professions and with no research findings for physical therapy graduate students. . $-6,11-13,15,16,31$ Further, a metaanalysis assessing the effects of El training in medical students showed that El can be improved which could potentially decrease stress in students. ${ }^{32}$

Personality type has been shown to relate to perceived stress in students. ${ }^{33}$ Swickert et al demonstrated positive correlations between extraversion and perceived availability of support, which has been found to play an important stress-buffering role when people experience high levels of stress. 34,35 Parkes found that extraversion correlated with improved coping abilities in stressful situations and decreased overall stress. ${ }^{36}$ Extroverted personality type has been broadly defined as individuals who are gregarious, seek excitement, and prefer sociability to social reservation. ${ }^{37-39}$ Previous research has found that physical therapy students generally score highly in extraversion personality trait. 40-41 De Raad and Schouwenburg showed that extroverted personality traits are expressed in learning styles and that these learning styles relate to feelings of self-efficacy in academic settings, resulting in lower levels of stress. ${ }^{42}$ More extroverted DPT students perform better on practical examinations, and one possible explanation is that an extroverted student experiences lower levels of stress in these settings, although this reason has not been confirmed. ${ }^{43}$

Open access self-report surveys are available to assess personality type. Goldberg's Big Five Personality test is a reliably validated self-report questionnaire demonstrating internal consistency and can be modified to accommodate user's needs. ${ }^{44}$ The Schutte Self Report Assessing Emotions Scale is a 33-item validated self-report measure of emotional intelligence. ${ }^{45}$ Respondents describe how much each statement describes them, utilizing a 5-point Likert scale ranging from 5 (strongly agree) to 1 (strongly disagree) with higher response scores indicating higher emotional intelligence. Perceived Stress Scale ${ }^{46}$ is a validated 10 item scale used to measure the degree to which individuals consider their life as stressful and was chosen as it measures perceived stress levels without loss of psychometric quality.

There exists evidence linking El to decreased perceived stress in undergraduate, medical, and nursing students and a lack of similar research involving DPT students. There is also research examining extroverted personality type and correlations with decreased perceived stress in students. There are findings related to extraversion and clinical performance as well as learning styles that may possibly relate to perceived stress. The purpose of the present study was to examine possible correlations between emotional intelligence, personality type, and perceived levels of stress of DPT students. It was hypothesized that higher extrovert personality bias, as well as higher levels of emotional intelligence, would correlate with lower levels of perceived stress.

\section{METHODS \\ Participants}

Participants included a convenience sample of 60 Doctor of Physical Therapy student volunteers (33 female, with age range 2338 years old), recruited from the 2019 (second-year students) and 2020 (first-year students) classes. The sample was composed of 28 first year students and 32 second year students. Potential participants were informed that participation was voluntary with no connection to grades or class standing and 60 of a possible 72 students chose to participate. Confidentiality was maintained by name removal and assignment of a numeric code to each participant before data analysis.

\section{Data Collection}

Prior to data collection, approval was granted by the Franklin Pierce University Institutional Review Board. Participants were emailed a link to an encrypted server that contained the consent form detailing anonymity and insuring that participation was separate from any coursework or class standing. Participants completed the consent form, followed by the El, extraversion, and perceived stress surveys, in that order. All participation occurred according to the schedule of participants, outside of a classroom and not during class time. After study participants provided consent to participate, they were administered first the Goldberg IPIPNEO, then the Assessing Emotions Scale, and finally the Perceived Stress Scale (PSS) questionnaires during the middle of the 
third study term. Study tools were accessed via encrypted email in the sequence above. The Goldberg IPIP-NEO is a self-reported questionnaire in which participants indicate their preference to different questions on a 5-point Likert Scale that reflects five different personality types. The 10 questions which addressed the extraversion domain are personality extraversion, agreeableness, conscientiousness, emotional stability, and imagination. Positively keyed extraversion items were given ascending scores as follows: 1 = Very Inaccurate, 2 = Moderately Inaccurate, $3=$ Neither Inaccurate nor Accurate, $4=$ Moderately Accurate, $5=$ Very Accurate. Negatively keyed items were given descending scores in a similar fashion with $5=$ Very Inaccurate scoring, $4=$ Moderately Inaccurate, 3= Neither Inaccurate nor Accurate, 2= Moderately Accurate, and 1= Very Accurate. The scored values were then summed for each participant to provide an overall score to describe extroversion or introversion bias. The minimum possible score for each subject was 10 with a maximum possible score of 50 . Scores closer to the minimum possible described individuals with high bias towards introversion whereas scores closer to the maximum possible described individuals with high preference towards extraversion. A score of 30 was considered neutral and described individuals with no clear tendency towards introversion or extraversion.

Table 1. Keyed Extraversion Items

\begin{tabular}{|l|l|}
\hline Positively Keyed Items & Negatively Keyed Items \\
\hline I am the life of the party. & I don't talk a lot. \\
\hline I feel comfortable around people. & I keep in the background. \\
\hline I start conversations. & I have little to say. \\
\hline I talk to a lot of different people at parties. & I don't like drawing attention to myself. \\
\hline I don't mind being the center of attention. & I am quiet around strangers. \\
\hline
\end{tabular}

The PSS was administered to have participants respond to how different situations affect their feelings and perceived stress. Positively keyed PSS items were given ascending scores as follows: $0=$ Never, $1=$ Almost Never, 2 = Sometimes, 3 = Fairly Often, and $4=$ Very Often. Negatively keyed items were given descending scores in a similar fashion with $4=$ Very often, $3=$ Almost Never, 2= Sometimes, $1=$ Fairly Often, and $0=$ Very Often. The score values were then summed for each participant to provide an overall score to determine their level of stress. Scores ranging from 0-13 are considered low stress, scores ranging from 14-26 are considered moderate stress, and scores ranging from 27-40 are considered high perceived stress.

Table 2. Keyed Perceived Stress Items

\begin{tabular}{|l|l|}
\hline Positively Keyed Items & Negatively Keyed Items \\
\hline $\begin{array}{l}\text { In the last month, how often have you been upset } \\
\text { because of something that happened unexpectedly? }\end{array}$ & $\begin{array}{l}\text { In the last month, how often have you felt confident about } \\
\text { your ability to handle your personal problems? }\end{array}$ \\
\hline $\begin{array}{l}\text { In the last month, how often have you felt that you were } \\
\text { unable to control the important things in your life? }\end{array}$ & $\begin{array}{l}\text { In the last month, how often have you felt that things } \\
\text { were going your way? }\end{array}$ \\
\hline $\begin{array}{l}\text { In the last month, how often have you felt nervous and } \\
\text { "stressed"? }\end{array}$ & $\begin{array}{l}\text { In the last month, how often have you been able } \\
\text { to control irritations in your life? }\end{array}$ \\
\hline $\begin{array}{l}\text { In the last month, how often have you found that you could } \\
\text { not cope with all the things that you had to do? }\end{array}$ & $\begin{array}{l}\text { In the last month, how often have you felt that you were on } \\
\text { top of things? }\end{array}$ \\
\hline $\begin{array}{l}\text { In the last month, how often have you been angered } \\
\text { because of things that were outside of your control? }\end{array}$ & \\
\hline $\begin{array}{l}\text { In the last month, how often have you felt difficulties } \\
\text { were piling up so high that you could not overcome them? }\end{array}$ & \\
\hline
\end{tabular}

The Assessing Emotions Scale was administered to participants and asks about their emotions or reactions associated with emotions in order to determine the level of emotional intelligence of each participant. Positively keyed items were given ascending scores as follows: Strongly disagree $=1$, Somewhat disagree $=2$. Neither agree nor disagree $=3$, Somewhat agree $=4$, and Strongly agree $=5$. Negatively keyed items were given descending scores in a similar fashion with Strongly agree $=1$, Somewhat agree $=2$, Neither agree nor disagree $=3$, Somewhat disagree $=4$, and Strongly disagree $=5$. Score values were then summed for each participant to provide an overall score to determine their level of emotional intelligence. Higher overall score indicate higher emotional intelligence.

Each of these tools have demonstrated validity and reliability for the respective areas measured ${ }^{33-35}$. Surveys were administered to students and results were analyzed for possible relationships between extraversion and stress levels as well as El and stress levels. 
Table 3. Keyed Emotional Intelligence Items

\begin{tabular}{|c|c|}
\hline Positively Keyed Items & Negatively Keyed Items \\
\hline I know when to speak about my personal problems to others. & $\begin{array}{l}\text { I find it hard to understand the non-verbal messages of other } \\
\text { people. }\end{array}$ \\
\hline $\begin{array}{l}\text { When I am faced with obstacles, I remember times I faced } \\
\text { similar obstacles and overcame them. }\end{array}$ & $\begin{array}{l}\text { When I am faced with a challenge, I give up because I } \\
\text { believe I will fail. }\end{array}$ \\
\hline I expect that I will do well on most things I try. & $\begin{array}{l}\text { It is difficult for me to understand why people feel the way } \\
\text { they do. }\end{array}$ \\
\hline \multicolumn{2}{|l|}{ Other people find it easy to confide in me. } \\
\hline \multicolumn{2}{|l|}{$\begin{array}{l}\text { Some of the major events of my life have led me to re- } \\
\text { evaluate what is important and not important. }\end{array}$} \\
\hline \multicolumn{2}{|l|}{ When my mood changes, I see new possibilities. } \\
\hline \multicolumn{2}{|l|}{ Emotions are one of the things that make my life worth living. } \\
\hline \multicolumn{2}{|l|}{ I am aware of my emotions as I experience them. } \\
\hline \multicolumn{2}{|l|}{ I expect good things to happen. } \\
\hline \multicolumn{2}{|l|}{$\begin{array}{l}\text { I motivate myself by imagining a good outcome to } \\
\text { tasks I take on. }\end{array}$} \\
\hline \multicolumn{2}{|l|}{$\begin{array}{l}\text { When I experience a positive emotion, I know how to make it } \\
\text { last. }\end{array}$} \\
\hline \multicolumn{2}{|l|}{ I arrange events others enjoy. } \\
\hline \multicolumn{2}{|l|}{ I seek out activities that make me happy. } \\
\hline \multicolumn{2}{|l|}{ I am aware of the non-verbal messages I send to others. } \\
\hline \multicolumn{2}{|l|}{$\begin{array}{l}\text { I present myself in a way that makes a good impression on } \\
\text { others. }\end{array}$} \\
\hline \multicolumn{2}{|l|}{$\begin{array}{l}\text { When I am in a positive mood, solving problems is easy for } \\
\text { me. }\end{array}$} \\
\hline \multicolumn{2}{|l|}{$\begin{array}{l}\text { By looking at their facial expressions, I recognize the } \\
\text { emotions people are experiencing. }\end{array}$} \\
\hline \multicolumn{2}{|l|}{ I know why my emotions change. } \\
\hline \multicolumn{2}{|l|}{$\begin{array}{l}\text { When I am in a positive mood, I am able to come up with } \\
\text { new ideas. }\end{array}$} \\
\hline \multicolumn{2}{|l|}{ I have control over my emotions. } \\
\hline \multicolumn{2}{|l|}{ I easily recognize my emotions as I experience them. } \\
\hline \multicolumn{2}{|l|}{$\begin{array}{l}\text { I motivate myself by imagining a good outcome to tasks I } \\
\text { take on. }\end{array}$} \\
\hline \multicolumn{2}{|l|}{ I compliment others when they have done something well. } \\
\hline \multicolumn{2}{|l|}{ I am aware of the non-verbal messages other people send. } \\
\hline \multicolumn{2}{|l|}{$\begin{array}{l}\text { When another person tells me about an important event in } \\
\text { his or her life, I almost feel as though I experienced this event } \\
\text { myself. }\end{array}$} \\
\hline \multicolumn{2}{|l|}{$\begin{array}{l}\text { When I feel a change in emotions, I tend to come up with } \\
\text { new ideas. }\end{array}$} \\
\hline \multicolumn{2}{|l|}{$\begin{array}{l}\text { When I am faced with a challenge, I give up because I } \\
\text { believe I will fail. }\end{array}$} \\
\hline \multicolumn{2}{|l|}{ I know what other people are feeling just by looking at them. } \\
\hline \multicolumn{2}{|l|}{ I help other people feel better when they are down. } \\
\hline \multicolumn{2}{|l|}{$\begin{array}{l}\text { I use good moods to help myself keep trying in the face of } \\
\text { obstacles. }\end{array}$} \\
\hline $\begin{array}{l}\text { I can tell how people are feeling by listening to the tone of } \\
\text { their voice. }\end{array}$ & \\
\hline
\end{tabular}

\section{Data Analysis}

Emotional intelligence and extraversion personality scores were both correlated with perceived stress scores with Spearman Rho analysis using SPSS program 25. 


\section{RESULTS}

\section{Sample Characteristics}

Participants included 33 females and 27 males with a mean age of $27.3 \pm 3.41$. The sample was composed of 28 first-year (PY1) students and 32 second-year (PY2) students. Results from Mann-Whitney $U$ tests showed that effects of both sex differences $(p=0.32)$ and graduate year $(p=0.27)$ on extraversion scores were insignificant as well as effects of both sex differences $(p=0.40)$ and graduate year $(\mathrm{p}=0.24)$ on $\mathrm{El}$ scores were insignificant.

Table 4. Participants: Effects of Graduate Year and Gender

\begin{tabular}{|l|c|c|c|c|c|c|}
\hline & PY1 & PY2 & p-value & Male & Female & $p$-value \\
\hline Extraversion & $32.87 \pm 8.17$ & $33.76 \pm 7.68$ & 0.28 & 33.14 & 35.34 & .36 \\
\hline $\begin{array}{l}\text { Emotional } \\
\text { Intelligence }\end{array}$ & $132.38 \pm 12.82$ & $128.69 \pm 12.95$ & 0.39 & 128.44 & 132.02 & .14 \\
\hline Perceived Stress & $14.85 \pm 5.89$ & $14.25 \pm 6.21$ & 0.26 & 14.38 & 14.51 & 0.18 \\
\hline
\end{tabular}

\section{Perceived Stress Scores}

Mean PS scores were $14.37 \pm 5.81$ (range 5-27) for first-year students and $14.52 \pm 6.65$ (range 3-25) for second-year students. Results from Mann-Whitney $\bar{U}$ test indicate differences in PS scores between first and second-year students were insignificant $(p=0.26)$. Additionally, no significant difference was found between sex and PS scores $(p=0.18)$. Total mean PS score was $14.45 \pm 6.17(p=0.14)$.

\section{Emotional Intelligence Scores}

Mean El score was $131.55 \pm 11.94$ (range: 101-159) for first-year students and $129.41 \pm 13.21$ (range: 98-155) for second-year students. Total mean El score was $130.41 \pm 12.90, p=0.24$. Total mean PS score was $14.45 \pm 6.17, p=0.14$. Mann Whitney U tests indicated no effect of either gender or graduate year on degree of El (see table 4).

\section{Extraversion Scores}

Mean extraversion score was $35.72 \pm 6.94$ (range: 19-50) for first-year students and $33.15 \pm 8.21$ (range: $21-45$ ). Total mean extraversion score was $34.35 \pm 7.48, p=0.24$. Total mean PS score was $14.45 \pm 6.17, p=0.14$. Mann Whitney $U$ tests indicated no effect of either gender or graduate year on degree of extraversion (see table 4).

\section{Correlation Analyses}

A Spearman Rho analysis was used to examine possible relationships between personality types and stress levels as well as emotional intelligence and stress levels. A significant weak negative correlation was found in this sample between emotional intelligence and perceived stress $\left(r_{s}=-0.291\right.$ with $\left.p=0.026\right)$. Results also indicated a weak negative correlation between extraversion and perceived stress $\left(r_{s}=-0.136\right.$ with $\left.p=0.305\right)$ which was not statistically significant.

Table 5. Correlation Analysis

\begin{tabular}{|l|l|l|l|}
\hline Emotional Intelligence & Perceived Stress & Spearman Rho & p-value \\
\hline $33.35 \pm 8.26$ & $14.53 \pm 6.12$ & -0.291 & 0.026 \\
\hline Extraversion & Perceived Stress & Spearman Rho & p value \\
\hline $33.35 \pm 8.26$ & $14.53 \pm 6.12$ & -0.136 & 0.305 \\
\hline
\end{tabular}




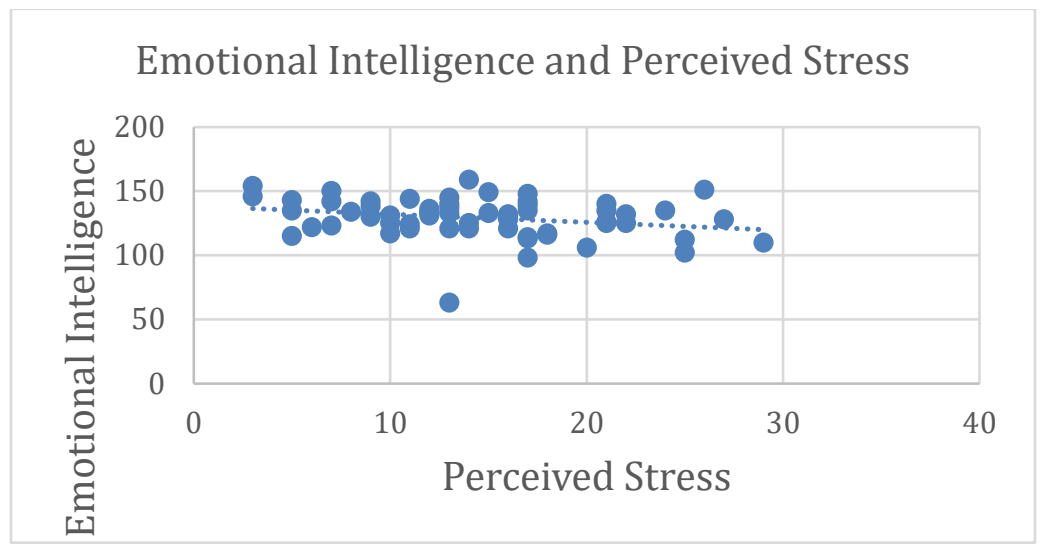

Figure 1. Scatter Plot Diagram: El and PS

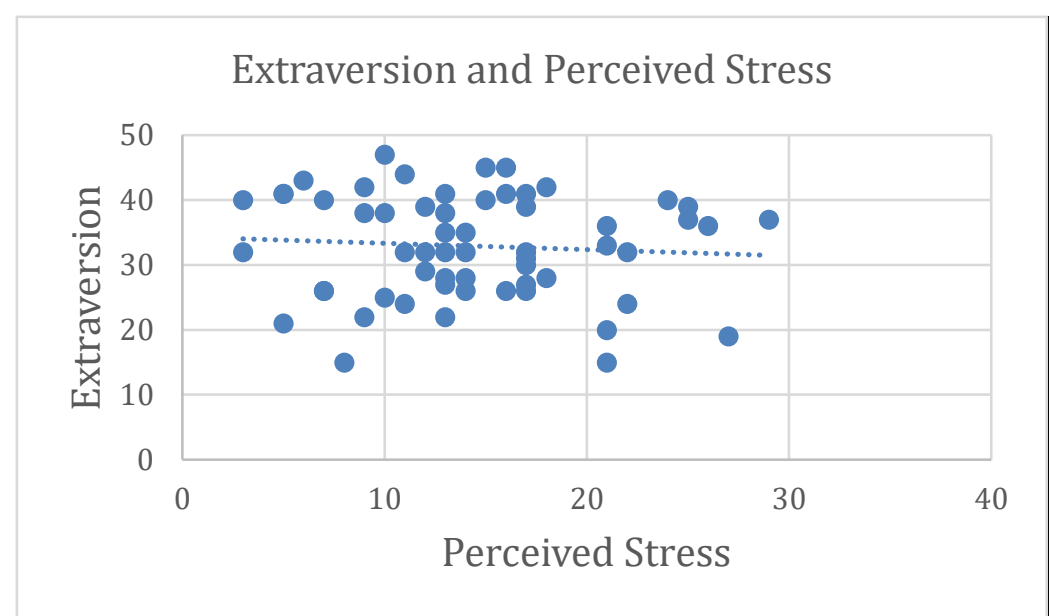

Figure 2: Extraversion and PS

\section{DISCUSSION}

A significant weak negative correlation was found between El and perceived stress in this group of DPT students. Previous studies have reported a negative correlation between El and perceived stress 1,4-6,11-13,15 in other student populations. While there are likely similiarities in causes of stress for all healthcare related students, no studies could be found assessing relationships between El and perceived stress in the DPT student population. All students experience stress due to examinations and deadlines. For some students preparing to be healthcare providers, patient interactions add an additional layer of stress. Therefore, the relationship between El and stress is of unique importance to these student populations. Further, the ability to improve El with training has important implications for healthcare students as improved El has been shown to increase clinical performance in dental students. ${ }^{32,47}$ Also,in a study examining El in surgeons, improved patient trust and patient relationships was found. ${ }^{48,49}$ Findings of the present study can be utilized by DPT programs in at least two ways. First, to assess applicants' emotional intelligence and determine appropriateness for a DPT program. 22,50 This data may also be evidence supporting the provision of El resources and training to matriculated students with lower emotional intelligence.

\section{Limitations}

Limitations of this study include the sequence of online survey completion by participants. Surveys were delivered in a step-wise format, with the IPIP first, then the El survey, with both followed by the PSS. It is possible that answers on one survey could have been influenced by a previous survey. It is also important to note that there is no conclusive evidence indicating that a student with lower El and higher perceived stress will perform poorly in a DPT program or fail to graduate. Further, El questionnaires are easily accessible online and therefore applicants can research answers to make themselves appear to have higher El. These findings may be best utilized in helping existing students to increase their El and find stress coping strategies to aid in their success throughout the course of the DPT program. Observations of students who perform well on written examinations and then 
experience performance stress during practical examinations resulting in low scores indicate a need for research measuring stress during specific tasks. The tool used to measure stress in the present study looks at perceived stress generally in the past month. Future research can be designed to focus more closely on stress experienced during specific tasks such as a practical exam. Future research should incorporate larger sample sizes and students from more than one DPT program. Additionally, a mixed methods design could include qualitative data about internal and external variables that may have contributed to findings.

\section{CONCLUSION}

DPT programs are continuously looking for ways to identify potential applicants with the traits necessary to become successful students and physical therapists. Additionally, programs aim to help current students reach their full potential in terms of academic achievement to facilitate understanding of key principles and to become competent healthcare professionals.. In this study we sought to determine if there was a relationship between personality type, emotional intelligence, and levels of perceived stress among physical therapy students. Given that DPT programs demand high levels of performance from students, high levels of stress are common, with DPT students shown to have higher levels of stress than age and gender matched peers ${ }^{9}$. Resources and training provided to DPT students can potentially increase El and reduce perceived stress. The findings of this study can be used to consider measuring El in applicants for DPT programs as well as when providing resources to matriculated DPT students with lower El levels.

\section{REFERENCES}

1. Birks, Y., McKendree, J., Watt, I. Emotional intelligence and perceived stress in healthcare students: a multiinstitutional, multi-professional survey. BMC Medical Education. 2009; 9(1), 61.

2. Bughi, S. A., Lie, D. A., Zia, S. K., \& Rosenthal, J. Using a personality inventory to identify risk of distress and burnout among early stage medical students. Education for Health. 2017; 30(1), 26.

3. Gupta, R., Singh, N., \& Kumar, R. Longitudinal predictive validity of emotional intelligence on first year medical students perceived stress. BMC Medical Education. 2017; 17(1), 139.

4. Naidoo, S. Emotional intelligence and perceived stress: scientific. South African Dental Journal. 2008; 63(3), 148-151.

5. Pau, A. K., \& Croucher, R. Emotional intelligence and perceived stress in dental undergraduates. Journal of Dental Education. 2003; 67(9), 1023-1028.

6. John, B., \& Al-Sawad, M. Perceived stress in clinical areas and emotional intelligence among baccalaureate nursing students. Journal of the Indian Academy of Applied Psychology. 2015; 41(3), 75-84.

7. Jacob, T., Gummesson, C., Nordmark, E., El-Ansary, D., Remedios, L., \& Webb, G. Perceived stress and sources of stress among physiotherapy students from 3 countries. Journal of Physical Therapy Education. 2012; 26(3), 57-65.

8. O'Meara, S., Kostas, T., Markland, F., \& Previty, J. C. Perceived academic stress in physical therapy students. Journal of Physical Therapy Education. 1994; 8(2), 71-75.

9. Frank, L. M., \& Cassady, S. L. Health and wellness in entry-level physical therapy students: are measures of stress, anxiety, and academic performance related? Cardiopulmonary Physical Therapy Journal. 2005; 16(4).

10. Ciarrochi, J., Deane, F. P., \& Anderson, S. Emotional intelligence moderates the relationship between stress and mental health. Personality and Individual Differences. 2002; 32(2), 197-209.

11. Das, I., \& Sharma, P. Relation between Myers Briggs psychological types and stress among university students. Indian Journal Of Health \& Wellbeing. 2015; 6(1), 62-67.

12. Extremera, N., Durán, A., \& Rey, L. The moderating effect of trait meta-mood and perceived stress on life satisfaction. Personality and Individual Differences. 2009; 47(2), 116-121.

13. Holinka, Cassandra. Stress, Emotional Intelligence, and Life Satisfaction In College Students. College Student Journal. 2015; 49(2), 300-311.

14. Kauts, Deepa S. Emotional intelligence and academic stress among college students. Educational Quest: an international journal of education and applied social sciences. 2016; 7(3),149-157.

15. Mikolajczak, M., \& Pena-Sarrionanda, A. On the efficiency of emotional intelligence training in adulthood. Emotion Researcher. 2015.

16. Ranasinghe, P. Emotional intelligence, perceived stress and academic performance of Sri Lankan medical undergraduates. BMC Medical Education. 2017; 17(1),1-7.

17. American Psychological Association. (2013). How stress affects your health. 
18. Rathus, S. A. "Stress, health, and adjustment." Psychology Concepts and Connections (2005): 479-513.

19. Deary, I. J., Watson, R., \& Hogston, R. A longitudinal cohort study of burnout and attrition in nursing students. Journal of Advanced Nursing. 2003; 43(1), 71-81.

20. Haack, M. R. Stress and impairment among nursing students. Research in Nursing \& Health, 1988; 11(2), 125-134.

21. Polman, R., Borkoles, E., \& Nicholls, A. R. Type D personality, stress, and symptoms of burnout: The influence of avoidance coping and social support. British Journal of Health Psychology. 2010; 15(3), 681-696.

22. Talib, N., \& Zia-ur-Rehman, M. Academic performance and perceived stress among university students. Educational Research and Reviews. 2012; 7(5), 127-132.

23. Akgun, S., \& Ciarrochi, J. Learned resourcefulness moderates the relationship between academic stress and academic performance. Educational Psychology. 2003; 23(3), 287-294.

24. Struthers, C. W., Perry, R. P., \& Menec, V. H. An examination of the relationship among academic stress, coping, motivation, and performance in college. Research in Higher Education. 2000; 41(5), 581-592.

25. Sohail, N. Stress and academic performance among medical students. J Coll Physicians Surg Pak. 2013; 23(1), 67-71.

26. Melaku, L., Mossie, A., \& Negash, A. Stress among medical students and its association with substance use and academic performance. J Biomed Educ. 2015; 1-9.

27. Megginson, L. Noncognitive constructs in graduate admissions: an integrative review of available instruments. Nurse Educator, 2009; 34(6), 254-261

28. Noorbakhsh, S. N., Besharat, M. A., \& Zarei, J. Emotional intelligence and coping styles with stress. Procedia-Social and Behavioral Sciences, 2010; 5, 818-822.

29. Sharon $D$, Grinberg $K$. Does the level of emotional intelligence affect the degree of success in nursing studies? Nurse Educ Today. 2018; 64: 21-26

30. Brackett, M. A., Rivers, S. E., Shiffman, S., Lerner, N., \& Salovey, P. Relating emotional abilities to social functioning: a comparison of self-report and performance measures of emotional intelligence. Journal of Personality and Social Psychology. 2006; 91(4), 780.

31. Enns A, Eldridge GD, Montgomery C, Gonzalez VM. Perceived stress, coping strategies, and emotional intelligence: A cross-sectional study of university students in helping disciplines. Nurse Educ Today. 2018;68:226-231.

32. Cherry, M. G., Fletcher, I., O'sullivan, H., \& Shaw, N. What impact do structured educational sessions to increase emotional intelligence have on medical students? BEME Guide No. 17. Medical Teacher. 2012; 34(1), 11-19.

33. Roohafza, H., Feizi, A., Afshar, H., Mazaheri, M., Behnamfar, O., Hassanzadeh-Keshteli, A., \& Adibi, P. (2016). Path analysis of relationship among personality, perceived stress, coping, social support, and psychological outcomes. World Journal of Psychiatry. 2016; 6(2), 248.

34. Swickert, R. J., Rosentreter, C. J., Hittner, J. B., \& Mushrush, J. E. Extraversion, social support processes, and stress. Personality and Individual Differences. 2002; 32(5), 877-891.

35. Cohen, S. Psychosocial models of the role of social support in the etiology of physical disease. 2003.

36. Parkes, K. R. (1986). Coping in stressful episodes: The role of individual differences, environmental factors, and situational characteristics. Journal of Personality and Social Psychology. 1986; 51(6), 127.

37. Ebstrup, J. F., Eplov, L. F., Pisinger, C., \& Jørgensen, T. Association between the Five Factor personality traits and perceived stress: is the effect mediated by general self-efficacy?. Anxiety, Stress \& Coping. 2011; 24(4), 407-419.

38. Fadda, D., \& Scalas, L. F. Neuroticism as a moderator of direct and mediated relationships between introversionextraversion and well-being. Europe's Journal of Psychology. 2016; 12(1), 49.

39. Furnham, A., Nuygards, S., \& Chamorro-Premuzic, T. Personality, assessment methods and academic performance. Instructional Science. 2013; 41(5), 975-987.

40. Hardigan, P. C., \& Cohen, S. R. A comparison of personality types among students enrolled in osteopathic, pharmacy, physical therapy, physician assistant and occupational programs: What the differences mean. Journal of the American Osteopathic Association. 1998; 98, 637.

41. Rovezzi-Carroll, S., \& Leavitt, R. Personality Characteristics and Expressed Career Choice of Graduating Physical Therapy Students. Physical Therapy. 1984; 64(10), 1549-1552. 
42. De Raad, B., \& Schouwenburg, H. C. Personality in learning and education: A review. European Journal of Personality. 1996; 10(5), 303-336.

43. Richardson, S., Zemanek, Z., Downen, T., Rich, C., \& Weltzin, N. The Effect of Extraversion On Practical Examination Sores in Students of Physical Therapy. Internet Journal of Allied Health Sciences and Practice. 2020; 18(2), 11.

44. Maples, J. L., Guan, L., Carter, N. T., \& Miller, J. D. A test of the International Personality Item Pool representation of the Revised NEO Personality Inventory and development of a 120-item IPIP-based measure of the five-factor model. Psychological Assessment. 2014; 26(4), 1070.

45. Schutte NS, Malouff JM, Hall LE, Haggerty DJ, Cooper JT, Golden CJ, Dornheim L. Development and validation of a measure of emotional intelligence. Pers Individ Dif. 1998; 25:167-77.

46. Cohen, S., Kamarck, T. and Mermelstein, R. A global measure of perceived stress. Journal of Health and Social Behavior. 1983; 385-396.

47. Victoroff, K. Z., \& Boyatzis, R. E. What is the relationship between emotional intelligence and dental student clinical performance?. Journal of Dental Education. 2013; 77(4), 416-426.

48. Weng, H. C., Steed, J. F., Yu, S. W., Liu, Y. T., Hsu, C. C., Yu, T. J., \& Chen, W. The effect of surgeon empathy and emotional intelligence on patient satisfaction. Advances in Health Sciences Education. 2011; 16(5), 591-600.

49. Weng, H. C., Chen, H. C., Chen, H. J., Lu, K., \& Hung, S. Y. Doctors' emotional intelligence and the patient-doctor relationship. Medical Education, 2008; 42(7), 703-711.

50. Roll, M., Canham, L., Salamh, P., Covington, K., Simon, C., \& Cook, C. A novel tool for evaluating non-cognitive traits of doctor of physical therapy learners in the United States. Journal of Educational Evaluation for Health Professions. 2018; 15. 